\title{
WRONGFUL LIFE/BIRTH: EL PROBLEMA DE DECIDIR QUÉ VIDAS MERECEN LA PENA SER VIVIDAS ${ }^{1}$
} A PROPÓSITO DEL CASO R.R. V. POLAND. (NO. 27617/04) ${ }^{2}$ JUZGADO EN POR EL TRIBUNAL DE ESTRASBURGO EL 26 DE MAYO DE 2011

\author{
WRONGFUL LIFE/BIRTH: THE PROBLEM TO DECIDE \\ WHICH LIVES DESERVE TO BE LIVED \\ ABOUT THE CASE R.R V. POLAND (APPLICATION N ${ }^{\circ}$ \\ 27617/04), TRIED BY THE STRASBOURG COURT ON MAY \\ $26 \mathrm{TH}, 2011$.
}

\section{Ursula Cristina Basset \\ ucbasset@gmail.com}

Recebido em: $31 / 08 / 2013$

Aprovado em: 08/10/2013

SUMARIO: 1. El caso R. R. V. Poland. 2. La decisión del Tribunal Europeo de Derechos Humanos. 3. Breves análisis del fallo. 4. El diagnóstico prenatal como acto jurídico complejo. 5. Un problema de fondo y algunas confusiones. 6. La perplejidad ante el reclamo por un niño vivo del que se alega que no debió haber nacido. 7. El nuevo humano y la tecnociencia. Referencias.

\section{RESUMEN}

A propósito de un reciente fallo del Tribunal Europeo de Derechos Humanos, que admite una demanda de daños y perjuicios del tipo "wrongful birth" contra Polonia, por una madre que por negligencia en el deber de informar del médico no pudo obtener oportunamente el aborto de su bija con sindrome de Turner. Al respecto, analizamos el marco de autonomía del acto médico y su valoración jurídica, el diagnóstico prenatal como un acto jurídico complejo y su calificación, los riesgos de discriminación genética, la relación entre vida y calidad de vida como bienes jurídicos tutelados, y
ABSTRACT

Abstract: About a recent decision of the European Court of Human Rights, that admits a claim on punitive damages deriving from "wrongful birth" against Poland, as a mother was not able to obtain timely abortion of her child due to her doctor's neglection, that failed in his duty to provide information. On the subject, we analyze the grounds of autonomy in the medical act and its legal appraisal, the pre-natal diagnosis as a complex legal act and its qualification, the riskes underlining genetic discrimination, the relation between life and quality of life, as legally protected interests, and the

1 Una versión anterior de este artículo fue publicada en la Revista de Derechos de las Personas y Familia, La Ley, Thomson Reuters. Esta versión está modificada y aumentada respecto de aquella.

2 Puede consultarse en el sitio del Tribunal Europeo de Derechos Humanos: http://cmiskp.echr.coe.int/ $\operatorname{tkp} 197 /$ view.asp?item $=53 \&$ portal $=$ hbkm\&action $=$ html\&highlight $=$ Poland\&sessionid $=76621533 \&$ skin $=$ hudoc-en 
la colisión entre derechos de autonomía, derechos de la mujer y derechos de la niñez. (iprincipio de autonomía y principio de beneficencia para la madre y para el hijo?). Como corolario se examina problemáticamente la ascendencia de nuevas teorías acerca de la conveniencia jurídica y bioética de sostener la vida humana en circunstancias que no son óptimas, de la definición de persona, de ser bumano, y la operabilidad de la condición bumana.

\section{Palabras-clave}

Tribunal Europeo de Derechos Humanos, derechos de autonomía, bioética, derechos de la mujer, derechos de la niñez: clash between autonomy rights, such as women's rights and children's rights (autonomy principle and beneficence principle for the mother and her child?). As a corollary, we problematized and study the ascension of new theories on the legal and bioethical convenience to support human life in non-optimal circumstances, definition of personality, of buman being, and the operability on the human condition.

Key words

European Court of Human Rights, rights of autonomy, bioethics, women's rights, children's rights.

\section{El caso R. R. V. Poland}

En el caso R. R. V. Poland el Tribunal Europeo de Derechos Humanos (TEDH) resuelve que una niña de 9 años de edad con síndrome de Turner debería haber podido ser abortada por su madre. La Corte Europea da derecho a toda madre de un niño con malformaciones genéticas a decidir abortar o continuar con el embarazo; y, en todo caso se entiende que, en atención a la carga que supondrá el cuidado de ese niño, la madre debe tener el derecho de poder decidir evitar la carga de ese niño, abortando mientras aún es posible.

El caso se puede resumir como sigue ${ }^{3}$. La Sra. R. R. queda embarazada en 2001 de una niña. Está casada y tiene dos hijos más. Al momento del embarazo, tiene 29 años de edad. En tres ocasiones durante el embarazo, en virtud de diversas ecografías, se advierte a la Sra. R. R. la posibilidad de la existencia de una malformación genética y la conveniencia de una amniocentesis para determinar de qué se trata (una punción para extraer líquido amniótico y analizarlo genéticamente). Para realizar este diagnóstico genético prenatal, el sistema de salud polaco requería la derivación por parte del médico de familia. Esa autorización estaba aparentemente ligada a la posibilidad de un aborto eugenésico según las leyes de Polonia. El médico de familia -el Dr. S. B.- se niega a realizar esa derivación porque entiende que la malformación que se advierte en las ecografías (no precisada, pero comprendiendo el síndrome de Turner entre las alternativas diagnósticas) no califica para un aborto eugenésico según la legislación vigente.

\footnotetext{
3 Siguiendo el detalle contenido en el mismo fallo.
} 
La Sra. R. R. y su esposo concurren conjuntamente a ver al Dr. S. B. y le exigen que realice una práctica abortiva. El Dr. S. B. se niega, porque entiende que las condiciones del aborto según la ley polaca no se verifican en este caso, y propone la convocatoria de un equipo médico para evaluar el caso. R. R. se niega a que su caso sea evaluado por un equipo médico.

Más adelante, admitida en un hospital, pide la consulta con el abogado del hospital para analizar si su caso encuadra en las leyes de Polonia. Así consigue ser derivada a un hospital especializado en abortos, a fin de realizar un diagnóstico más amplio. Se le advierte que el aborto en este caso comportaría además riesgos para la salud de la madre, al igual que la práctica de la amniocentesis (aspecto no valorado por la sentencia, pero mencionado en los prolegómenos).

R. R. concurre al hospital especializado y se confirma necesidad del diagnóstico genético, la existencia de una malformación. Pide una derivación para el test genético (vinculado con la práctica abortiva) y el médico se niega porque se considera incompetente para emitirlo. R. R. refiere que el médico le dijo (no hay constancia de esto) que no emitiría la derivación porque ella tenía la intencionalidad de realizar el diagnóstico para abortar.

Luego de diversas complicaciones burocráticas, R. R. finalmente consigue realizar el diagnóstico prenatal. En todas las instancias, la Sra. R. R. asocia su pedido a una expresa demanda de abortar a la niña en gestación. Para ese entonces finaliza la semana 22 de su embarazo y como el feto es viable para la vida extrauterina, los médicos se niegan a practicar el aborto, amparados por la ley en vigencia.

La niña nace en 2002, con síndrome de Turner. La madre inicia acciones legales. Las acciones criminales son rechazadas por los tribunales. Las acciones civiles para obtener reparaciones llegan a la Corte Suprema de Polonia, en dónde se decide:

- Que los médicos estaban obligados a brindar información a la madre sobre el estado de salud del feto, según la legislación vigente 4 .

- Que si los médicos hubieran tenido objeción de conciencia, debieron haberla manifestado oportunamente; a fin de que otro profesional que no la tuviere, llevara adelante la práctica.

- Que la Sra. R. R. había sufrido daño moral por la manera en que había sido manejado su caso ${ }^{5}$.

- Que la madre tiene derecho a acceder a la información genética del feto ${ }^{6}$ en orden a decidir si continúa o no con el embarazo (como decisión concerniente a su esfera de privacidad).

\footnotetext{
Parágrafo n. 101, RR v. Poland.

Parágrafo n. 102, RR v. Poland.

Ibid. Y Parágrafo 54, RR v. Poland.
} 
- Que el hecho de que el niño hubiera nacido, como resultado de que los médicos no hubieran realizado el diagnóstico prenatal a tiempo, es suficiente como para generar un derecho al resarcimiento económico de la madre.

Podría pensarse que el asunto era caso cerrado, toda vez que la demandante había obtenido un interesante resarcimiento económico de todas las partes (incluso del médico de familia y del hospital). Sin embargo, la Sra. R. R. consideró que se habían violado derechos bajo la Convención Europea ${ }^{7}$ y asesorada por diversas organizaciones no gubernamentales que promueven el reconocimiento del aborto como derecho humano, accedió a la instancia del Tribunal Europeo ${ }^{8}$. El TEDH sostuvo también que la jurisdicción constitucional polaca no tiene un mecanismo para aplicar la legislación constitucional al caso concreto?.

\section{La decisión del Tribunal Europeo de Derechos Humanos}

A continuación desarrollaremos las ideas principales que recorren el fallo del TEDH.

i. La negativa temporánea a realizar un diagnóstico prenatal genético constituye un trato cruel, inbumano y degradante

Por seis votos contra uno se decide encuadrar el caso en el Art. 3 de la Convención Europea de Derechos Humanos, que prohíbe el trato inhumano, cruel o degradante. Entiende que la Sra. R. R. en la medida en que no se le garantizó el acceso a la información en su estado de especial vulnerabilidad por la posibilidad de tener que alumbrar a una niña con malformaciones y la postergación a su derecho a decidir privadamente si abortaba o no; recibió un trato cruel inhumano o degradante ${ }^{10}$. Con esta decisión la Corte amplifica la restringida aplicación previa de la noción, dando cauce a nuevos encuadres dentro de la misma.

7 Parágrafo 104 y ss., RR v. Poland. La Corte entiende que la indemnización debe ser revisada teniendo ante la vista las circunstancias del caso, como un todo. ("...the Court is of the view that the amount awardded at the domestic level must be viewed against the background of the case seen as a whole. )... It is in this context that the adequacy of the award made in the civil proceedings must be assessed." 104-105).

8 Así lo refiere expresamente la Federación Polaca de Planeamiento Familiar para las Mujeres: “The Federation for Women and Family Planning expresses a great satisfaction with landmark judgment of the European Court of Human Rights in Strasburg in the case R.R. v. Poland, which states that Poland has violated the articles of the European Convention on Human Rights. The Federation is even more pleased as the R.R. case was conducted by our organization in cooperation with the Warsaw University Law Clinic, supported by the Center for Reproductive Rights. Att. Monika Gasiorowska and Irmina Kotkiuk, who conducted the case at the Court, are members of the Federation's Network of Lawyers." Véase la abogacía pro-aborto en KLUGMAN; BUDLENDER, 2001.

9 Parágrafo 116-117, RR v. Poland.

10 Parágrafo 161, RR v. Poland. 
ii. La negativa al derecho a la información sobre la salud fetal y el consecuente bloqueo a la posibilidad de decidir un aborto es una violación del derecho a la privacidady vida familiar

Por seis votos contra uno, encuadrar el caso en el Art. 8 de la CEDH, concluyendo que se había producido una infracción a la vida privada y familiar de la Sra. R. R. al negarle el acceso a la información del diagnóstico prenatal genético. En este sentido, merece la pena destacar los siguientes aspectos de la decisión mayoritaria:

- El derecho a la vida privada y familiar comprende el derecho a decidir la integración de la constelación familiar. El TEDH entiende que la noción de vida privada implica también las decisiones de "tener o no tener un hijo o convertirse en padres"11. Una madre tiene derecho a decidir cuántos hijos quiere tener y de qué manera quiere configurar su vida familiar. Aún luego de haber decidido autónomamente concebir un hijo, no está obligada a llevar a término ese embarazo como derecho emergente de la privacidad familiar ${ }^{12} \mathrm{y}$ según la regulación del Estado parte de que se trate ${ }^{13}$.

- En el conflicto de intereses entre la madre y el feto, rige el margen de apreciación, aunque considerando que es restringido, porque la mayoría de los Estados-parte admiten el aborto. Aunque sea un argumento que luego no se desarrolla, el TEDH también dice que "resulta claro del análisis de estos casos que el asunto siempre fue determinado por el balance de varios intereses -eventualmente opuestos- por la madre o el padre, de cara al feto"14.

- Polonia está obligada no sólo a proveer leyes que garanticen el derecho a la información, como acceso al derecho de decidir interrumpir o no el embarazo; sino también a que dichas leyes sean de cumplimiento efectivo en la práctica ${ }^{15}$. Para ello, el hecho de que por razones diversas los médicos hayan demorado el diagnóstico genético ha sido crucial, puesto que impidió a la madre ejercer su derecho a decidir ${ }^{16}$.

- El TEDH reconoce el derecho a la objeción de conciencia, sin embargo ese derecho no puede impedir que se concrete la obligación del Estado de brindar un servicio de salud, o el acceso a la información sobre la salud

11 Parágrafo 180, RR v. Poland. "The Court has also held that the notion of private live applies to decisión both to have or not to have a child or to become parents", con cita de Evans v. UK (n. 6339/05).

12 Parágrafo 181, RR v. Poland.

13 Parágrafo 183, RR v. Poland.

14 Parágrafo 181, RR v. Poland. "It si also clear from an examination of these cases that the issue has always been determined by weighing up various, and sometimes conflicting, rights or freedoms claimed by a mother or a father in relation to one another vis à vis the foetus." En este caso cita el caso de Vo v. France, en el que por error médico se produce un aborto no querido por la madre.

15 Parágrafos 183-185, RR. v. Poland.

16 Parágrafo 188 y 197-200, RR. v. Poland. 
del feto. Si algunos médicos sintieran una colisión con sus principios morales, el Estado debería garantizar que otros profesionales prestaran ese mismo servicio ${ }^{17}$.

- El TEDH entiende que Polonia debió haber proveído además mecanismos procesales adecuados para que la víctima hubiera podido ejercer su derecho de hacer cumplir el diagnóstico genético. La Corte considera que garantizar un resarcimiento retroactivo por vía civil en virtud del daño causado por la demora en el diagnóstico prenatal genético, bloqueando definitivamente el ejercicio de la autonomía de la voluntad de la madre para abortar a su hija; no satisface suficientemente la exigencia del respeto a la vida privada y familiar del Art. 9 de la $\mathrm{CEDH}^{18}$.

- La víctima no agotó su instancia en la Corte polaca, porque ésta sólo aseguro remedios retrospectivos $y$ no medios procesales efectivos (prospectivos) para que la víctima pudiera garantizar sus derechos a la información y a decidir $^{19}$. La mujer encinta está en una posición especialmente vulnerable (nos preguntamos en qué posición de vulnerabilidad está su hija con síndrome de Turner). En consecuencia, deben garantizársele los medios procesales para acceder a la ejecutoriedad del derecho al acceso a la información.

iii. La falta de mecanismos políticos y procesales para prevenir el resultado merece
sanción

Polonia ha violado también el Art. 13 de la CEDH, por no proveer mecanismos para que las violaciones de derechos humanos puedan ser prevenidas y reparadas por mecanismos adecuados. Vale decir, no se le objeta la falta de regulación de hipótesis de aborto, sino la falta de previsión en torno a hipótesis de conflicto que acaba por ser vulneratoria de la privacidad de quienes pretenden acceder al aborto y consideran que su supuesto encuadra en la previsión legal. No obstante, para asegurar que el caso concreto encuadra en el tipo previsto, requieren el diagnóstico prenatal. Si el acceso a dicho diagnóstico obliga a la parte requirente a recurrir a un procedimiento que resulte lesivo a su vida privada familiar, entonces se habrá producido una infracción al Art. 8 de la CEDH. En el caso concreto el TEDH entiende que Polonia no ha garantizado dichos mecanismos. No desarrolla su posición al respecto, ni explicita cómo podría Polonia haber ofrecido mecanismos adecuados de regulación (lo cuál parece prudente, toda vez que no es función del Tribunal dictar políticas internas, sino sólo señalar contradicciones con el marco europeo de los derechos humanos). Para el voto de la mayoría del TEDH, Polonia 
no prevé un marco normativo adecuado que permita resolver conflictos en torno a la accesibilidad al diagnóstico prenatal sin vulnerar la vida privada familiar ${ }^{20}$.

\section{iv. Los votos en disenso}

Dos votos en disenso contiene el fallo. El primero simplemente objeta la dilatación del concepto de tratos inhumanos y degradantes. El segundo objeta el encuadre bajo el Artículo 8 del particular y lo firma el juez maltés de Gaetano. Éste último se refiere a la pusilanimidad del TEDH en defender el derecho a la vida del no nacido. Para él, no era competencia de la Corte ingresar en el margen de apreciación del Estado al limitar los casos efectivamente admitidos para la práctica abortiva.

\section{v. Sanción económica para Polonia}

Por el Art. 41 se impone a Polonia un resarcimiento de Euros cuarenta y un mil a favor de la víctima.

\section{vi. Breve excurso sobre el término "wrongful" unido a los términos "birth" or "life"21}

Antes de pasar al relato y análisis del caso a comentar, conviene un breve paseo narrativo 22 sobre la denominación de este tipo de acciones. Es necesario sentar que el término "wrongful" es un adjetivo que califica a "birth" (nacimiento) o "life" (vida). Ese término puede calificar un sinnúmero de otras circunstancias, por ejemplo: un despido, una adopción o una muerte pueden ser "wrongful" y como tal, dar curso a una acción de reclamación por los daños causados. De modo que no cabe utilizar el término sin el sustantivo al que califica.

20 Parágrafos 215-218, RR. v. Poland. Específicamente el parágrafo 218 en el que el Tribunal expresa su parecer sobre el asunto, refiere a la falta de previsión de mecanismos adecuados en el caso de emergencia de conflictos derivados de la normativa vigente em torno a la procedência del diagnóstico prenatal, en tanto que viola el Art. 8 de la CEDH. Lo transcribimos: "218. The Court observes that the applicant's complaint about the State's failure to put in place an adequate legal framework allowing for the determination of disputes arising in the context of a determination of access to diagnostic services relevant for the application of the 1993 Act, insofar as it allowed for legal abortion, essentially overlaps with the issues which have been examined under Article 8 of the Convention. The Court has found a violation of this provision on account of the State's failure to meet its positive obligations. It holds that no separate issue arises under Article 13 of the Convention (see Tysiąc v. Poland, cited above, $\$ 135$ ).” De todas formas, como se advierte, el TEDH no profundiza estos aspectos.

21 Agradezco a Natalia Torres Santomé, que me hizo llegar un artículo inédito de ella a publicar en una obra colectiva, sobre esta materia de próxima aparición.

22 En homenaje a la obra de Umberto Eco. 
El significado del término "wrongful" asociado a vida o nacimiento es mucho más complejo de precisar, porque se trata de una asociación inconmensurable en la mayoría de las traducciones posibles (probablemente suceda lo mismo en el lenguaje matriz). El conocido Black's dictionary, en su edición de 2004, define:

\begin{abstract}
"wrongful, adj. 1. Characterized by unfairness or injustice <wrongful military invasion>. 2. Contrary to law; unlawful <wrongful termination>. 3. (Of a person) not entitled to the position occupied $<$ wrongful possessor $>$.wrongful act. See wrongful conduct. wrongful conduct. An act taken in violation of a legal duty; an act that unjustly infringes on another's rights - Also termed wrongful act."23
\end{abstract}

Como se evidencia, nos sirven aquí totalmente los diccionarios jurídicos puesto que las acepciones generales no son del todo aplicables ${ }^{24} \mathrm{y}$ las específicas relativas a vida y nacimiento, traen un concepto de las acciones "wrongful life/birth" 25 . Sin embargo, no definen suficientemente el vocablo de la discordia explicando la significación que tiene en ese preciso giro. En cambio, el Merriam Webster's define wrongful como pleno de maldad, pero también injusto o que carece de acción de reclamo (¿traduciríamos que no hay derecho subjetivo para tal cosa? $)^{26}$.

Una enciclopedia francesa dirigida por el conocido filósofo y bioeticista belga Gilbert Hottois traduce el giro como "vie préjudiciable" (HOTTOIS; MISSA, 2001, p. 862). Esta denominación resulta confirmada por un interesante estudio canadiense de "normalización" lingüística en materia de derecho de daños, que concluye que la traducción más apropiada sería la de "vida perjudicial" (CHÉNARD, 2007). Gérard Mémeteau, el reconocido jurista de Poitiers especializado en derecho médico, ha traducido "vie dommageable" (MÉMÉTEAU, 2000, I, p. 279), probablemente en

23 “Caracterizado por injusticia (invasión militar injusta); 2. Contrario a la ley, ilegal (conclusión ilegal -N. T. de un contrato, de un contrato laboral); 3. (Referido a una persona) no poseedor de un título para la posición ocupada (poseedor ilegítimo). 4. Acto. Ver conducta "wrongful" Un acto cometido en violación de un deber legal o un acto que injustamente viola los derechos de otros. También denominado 'wrongful act"'.

24 Según el estudio lingüístico de Isabelle Chénard (2007), sólo el primero de los significados del Black’s Dictionary se podrían aplicar a las acciones de wrongful life/birth.

25 Según el Black's los dos últimos significados no se aplicarían a los giros compuestos de "wrongful life/birth/ pregnancy". Estos son definidos en términos de acciones. "Wrongful-birth action" es una acción contra un medico por fallar al aconsejar a los padres de manera prospectiva sobre los riesgos que devendrían para ellos de tener un niño con defectos". La acción "wrongful life" es llevada adelante en representación del niño con defectos de nacimiento, alegando que si no fuera por el consejo negligente del médico demandado, los padres no habrían concebido el niño, o si lo hubieran concebido, lo hubieran abortado en orden a evitar la pena y el sufrimiento resultante de los defectos congénitos del niño. El diccionario concluye que la mayoría de los juristas rechazan estas acciones. ("wrongful-birth action. A lawsuit brought by parents against a doctor for failing to advise them prospectively about the risks of their having a child with birth defects. wrongful-life action. A lawsuit brought by or on behalf of a child with birth defects, alleging that but for the doctor-defendant's negligent advice, the parents would not have conceived the child, or if they had, would have aborted the fetus to avoid the pain and suffering resulting from the child's congenital defects. - Most jurisdictions reject these claims.”, Black's Dictionary, 2004).

26 Definition of WRONGFUL : 1. wrong, unjust 2 a: having no legal sanction : unlawful b: having no legal claim $<$ a wrongful heir $>$ 
el sentido de dañosa ${ }^{27}$, pero con los sinónimos de funesto o nefasto. Pero ni "vida perjudicial" ni "vida dañosa" resultan totalmente apropiadas traducciones. Una vida no es perjudicial en si misma sino en relación. En consecuencia, si la vida perjudica o daña, debe inquirirse a quién. $\mathrm{Y}$ así se desenvuelven las cataratas de enigmas en torno a los presupuestos tradicionales de responsabilidad, que quedan invariablemente sin respuesta.

En español, se ha dicho que puede traducirse como "vida inapropiada" (ROMERO COLOMA, 2009), o "vida errónea, si se opta por una traducción literal" (PARDO, 2010, p. 91 y ss). No se ve claro.

Vida inapropiada respecto de qué finalidad vital. La idea de télesis debe guardarse de los riesgos de una hermenéutica utilitarista respecto de la concepción de la humanidad. Un severo daño cerebral (p. ej. parálisis cerebral?) deja a ese ser humano en un estado inapropiado para la humanidad, puesto que las facultades de raciocinio están permanente perturbadas hasta el actual desarrollo de la ciencia, al menos. Un ejemplo de este supuesto sería el caso de la anencefalia: un ser humano inapropiado (¿equivalente a "inviable”?), por no alcanzar estándares propios de la humanidad raciocinante y eso de manera permanente. Es inevitable preguntarse qué hace humano al humano, a sabiendas de las implicancias jurídicas y morales de la respuesta. ¿Un ser vivo con $\mathrm{ADN}$ humano puede pertenecer a una especie infrahumana -no en sentido metafórico, sino en sentido científico específico-? Es, sin ir más lejos, la propuesta de Hugo Tristram Engelhardt Jr. (1996, pp. 135 y ss.) $)^{28}$, cuando distingue entre ser humano y persona. ¿Como si fueran dos especies dentro de un mismo género? ¿Unas accederían al status de derechohabientes (sui iuris), otras en cambio serían alieni iuris, por carecer de autonomía? No es la perspectiva de la Decl. Univ. De Derechos Humanos, para la cual todo ser humano en todo lugar tendría derechos a la personalidad jurídica ${ }^{29}$, pero tal vez es la perspectiva teórica de una parte importante de la doctrina y de la legislación. De hecho es en este contexto es que Engelhardt introduce el término "competencia".

Pese a lo que pudiera parecer, las preguntas no son retóricas. Son acuciantes paradigmas culturales los que están en discusión, que podrían provocar un salto cualitativo (a juzgar si para bien o para mal) en torno a la comprensión jurídica de la idea de humanidad y la protección jurídica que se debe dar a los derechos que emanan de ella. La evolución de algunos miembros de la especie humana podría ser involutiva, en torno a la comprensión de sí mismos, haciendo prevalecer nuevos atavismos selectivos. La duda es cuál comprensión de lo humano es más humana.

27 Según el Grand Dictionnaire de Larousse.

28 La persona, a diferencia del ser humano, es "self-conscious, rational, free to choose, and in posession of a sense of moral concern" (ENGELHARDT, 1996, p. 136). Pore so sostiene que "Not all humans are equal". Las personas son "competentes" los seres humanos no lo son.

29 Art. 6, Declaración Universal de Derechos Humanos (1948). 
Paralelamente, la vida errónea significa que alguien se equivocó (¿la naturaleza? ¿la madre? ¿el médico?). Ni el antropomorfismo respecto de la naturaleza, ni la madre -que puede ser causante de un daño genético -en ese caso el error es de la madre y no de la "vida"-, ni el médico -mismas consideraciones-; dan cuenta de esa designación.

Es difícil traducir wrongful life como vida injusta, porque el término "injusticia" toda vez que califica una desigualdad objetiva entre dos títulos que deberían ser igualados no puede predicarse de una sola vida. Las vidas no son justas o injustas. En todo caso puede predicarse: "es justo o no que éste viva", con el escalofrío consecuente.

En síntesis, no hay traducción posible y ya de entrada se advierte que la idea de wrongful life es incomensurable, y hasta cierto punto, imposible metafísicamente. No obstante, como acabamos de ver, alguna jurisprudencia considera admisible el resarcimiento por "vidas dañosas".

\section{Breves análisis del fallo}

A continuación, simplemente unas pocas y breves reflexiones sobre el caso. El fallo tiene muchísimas vertientes, aquí rozaremos apenas algunas.

\section{i. El derecho y sus límites epistemológicos}

En primer lugar, es falso que no haya habido un diagnóstico prenatal en el caso. Lo hubo y en reiteradas ocasiones ${ }^{30}$. Incluso hubo la amniocentesis solicitada por la demandante. En numerosas ocasiones se verificó la existencia de malformaciones genéticas. Pero los médicos consideraron que en el marco de la legislación interna sobre el aborto, dichas malformaciones no eran suficientes como para habilitar la práctica abortiva.

En este sentido, es notable que el derecho ignore la prudencia médica expost ${ }^{31}$ . El médico valora en el momento y toma decisiones según lo que experimenta del caso concreto, privilegiando el mandato hipocrático. El jurista necesariamente realiza una extrapolación anacrónica aislada de numerosas circunstancias concretas que informan el diagnóstico médico y que es imposible hacer constar en una historia clínica de manera absoluta y exhaustiva.

30 Ver las variantes del diagnóstico prenatal en LAFFERRIÈRE (2010, pp. 67-84).

31 En este sentido, valen las interesantes consideraciones de J. Nicolás LAFFERRIÈRE en Implicaciones..., cit., cuando se refiere a la inconveniencia de legislar y en cambio valora la conveniencia del respeto al acto prudencial médico (2010. p. 468 y ss.). 
De esta manera, el jurista se erige en una suerte de ojo universal metacientífico, que avasalla las fronteras del saber sin respetar sus premisas propias. El dogmatismo jurídico rígido corre el riesgo de convertir al jurista en una suerte de conciencia moral colectiva, con el poder de controlar y decidir si el acto de un especialista cuyo ámbito de decisión es resguardado. El médico ofrece sus horas para curar, los errores son indudablemente censurables pero sólo a partir del respeto de su ámbito propio de decisión y conociendo que el caso concreto siempre tiene algo de inescrutable. De ahí que cuando le preguntaron al gran jurista francés Philippe Malaurie cuál era la virtud más importante del derecho, contestó: "La humildad”32.

\section{ii. Diagnóstico prenatal como acto médico}

Es muy difícil abordar el asunto del diagnóstico prenatal luego de la conclusiva obra recientemente publicada por el profesor argentino J. N. Lafferrière sobre el particular (LAFFERRIÈRE, 2010). Allí, el autor define el diagnóstico prenatal en los siguientes términos:

[...] el diagnóstico prenatal es el acto médico de conocimiento de la condición de la salud del niño por nacer, auxiliado por técnicas instrumentales y de laboratorio, a fin de individualizar patologías, realizar un pronóstico y elaborar estrategias preventivas, terapéuticas o paliativas en beneficio del concebido y, en su caso, de asesoramiento y contención profesional a la madre y al padre para la aceptación y cuidado del hijo enfermo (LAFFERRIÈRE, 2010, p. 40).

Es fundamental el encuadre que el autor realiza, luego de discutir ampliamente conceptualizaciones jurídicas posibles. Para ello recurre con gran atino, a la inquietante idea de "biotecnociencia" como un recurso teórico eventualmente distorsivo de la complejidad propia del acto diagnóstico.

El concepto de "tecnociencia" fue introducido aparentemente por el belga Hottois, que ya hemos citado, a fines de la década del setenta. Para él, la tecnociencia hoy, es una concepción metafísica, con aspiración de totalidad. La antigua pregunta que se formulaban los griegos en punto a qué es el ser, queda respondida en la actitud colectiva tecnocientífica:

La tecnociencia contemporánea no es sino la concretización operatoria del proyecto de dominio absoluto y totalitario característico de la metafísica. (...) Al término de esta historia, ¿qué tenemos ? Una physis -la naturaleza- objetivada y operacionalizada, reducida a un fondo de energías y materias explotables sin algún limite; una concepción de la técnica como conjunto de medios al servicio del designio humano de manipulación y de explotación universal. Ellos se aplican también al hombre en tanto que forma parte de la naturaleza objetivada y operable. (HOT'TOIS)

32 Anécdota que él mismo narró en forma verbal este mes de julio en Lyon, respecto de una conversación que mantenía con su hija. 
Si el ser es entendido como " physis » (y probablemente no en el sentido griego del término), y la naturaleza como el campo al que se extiende el dominio del hombre, el hombre pertenece a su propio campo de dominio, convirtiéndose así él mismo en una naturaleza objetivada y operable.

En cambio, el encuadre en el acto humano cambia sustancialmente la perspectiva. El acto humano -como saben también los juristas- se distingue incluso del acto del hombre, por su naturaleza moral. El acto médico encuadra en la naturaleza propia del acto eminentemente humano, en el sentido jurídico, pero también en el sentido vulgar del término "humano": en el sentido de la empatía, del com-padecer con los semejantes, vale decir, con los pacientes a quienes toca diagnosticar. Esta segunda dimensión, no jurídica, suele estar empero incluida en los protocolos médicos de información diagnóstica.

\section{El diagnóstico prenatal como acto jurídico complejo}

En segundo lugar, quisiéramos analizar algunos párrafos del fallo que hacen alusión al diagnóstico prenatal genético, como un acto médico (jurídico y ético) independiente de la práctica abortiva. El TEDH sostiene que se trata de dos actos distintos y separados entre los que no existe nexo o ligamen jurídico alguno. Nosotros vamos a contender en este artículo que entre ambos actos existe un ligamen jurídico que permite identificar una unidad de sentido, para calificar la licitud o ilicitud del mismo. Para ello, analizaremos en un breve excurso la noción de complejidad de los actos jurídicos, para luego analizar su aplicación a este supuesto.

\section{i. El ligamen jurídico en los actos jurídicos complejos}

Hace unos quince años, se publicaba un artículo de los autores argentinos M. F. De Lorenzo y J. W. Tobías sobre el negocio jurídico complejo (DE LORENZO, TOBÍAS, 1996-D, 1387). En él, los autores describían a todo evento esta complejidad de la siguiente forma:

Suele observarse en la práctica negocial la existencia de dos o más negocios jurídicos --cada cual, por lo tanto, autónomo e independiente y productor de efectos jurídicos propios-- que se encuentran, sin embargo, unidos por una cierta conexión o ligamen cuya intensidad y naturaleza varían según los casos."

Con respecto al elemento determinante del ligamen negocial de los actos complejos, se han adoptado diversas posiciones en la doctrina. 
- La voluntad de las partes. De una parte, algunos teóricos entienden que la voluntad de las partes es la que causa el ligamen. La teoría subjetivista fue contestada por cuanto las partes no siempre son conscientes de una voluntad plural o única.

- El objeto del acto. Los actos están conectados por un mismo objeto. Pero esta teoría no se sostiene, toda vez que los actos se distinguen por el objeto. Si los actos tuvieran objetos distintos, necesariamente serían actos distintos. Eso no explicaría la conexión entre actos con diversos objetos.

- Teoría ecléctica. La teoría ecléctica procura integrar los diversos actos en virtud de la unidad económica entre las diversas prestaciones, pero ha sido similarmente criticada.

- Teoría finalista. Es probablemente la más interesante. Ella sostiene que es la causa fin la que une los diversos actos. Todos ellos constituyen una unidad, causada por el único fin que enhebra los actos jurídicos. Esta última es la sostenida por los autores del interesante artículo que seguimos, con fundamento en notable doctrina italiana.

La teoría finalista es la única capaz de explicar efectivamente la unidad de sentido que se produce entre determinados actos jurídicos, en los cuáles unos están enlazados con otros en una estructura moral y jurídica compleja.

\section{ii. La calificación jurídica como lícito o ilícito de un acto jurídico complejo}

De Lorenzo y Tobías explican aún que la calificación jurídica de la estructura compleja de actos, unificada por su finalidad intencional está determinada precisamente por la licitud o ilicitud de la causa fin. Vale decir que, encontrándose los actos enlazados entre si, si la finalidad perseguida es ilícita, la unidad de sentido que dichos actos producen, deviene ilícita.

\section{iii. Aplicación al caso en análisis}

Aplicando esta exploración en la teoría de los actos complejos al caso del diagnóstico prenatal, éste no puede ser interpretado, como pretende el TEDH, como un acto aislado de su entramado de sentido.

En el caso que nos toca analizar, la Sra. R. R. ni siquiera por su autonomía de la voluntad lo entendió así. Siempre fue transparente en su intencionalidad abortiva en el supuesto de que emergiera una malformación. Incluso exigió el aborto antes de haberse precisado cuál era exactamente la naturaleza de esa malformación. La cadena de actos integrada por el diagnóstico prenatal y el aborto, estaba impulsada y enhebrada indisolublemente por una sola causa fin: abortar por eugenesia. El caso es que los médicos que la evaluaron, consideraron que el síndrome de Turner no habilitaba la práctica abortiva ni encuadraba en el texto de la ley polaca. Es decir, 
el acto médico evaluó el caso concreto como un todo, incluyendo la intención de fin y el fin en la decisión que derivó en el acto médico que supuso una negativa a la práctica del diagnóstico prenatal.

\section{Un problema de fondo y algunas confusiones}

Algunas confusiones han sido señaladas por la doctrina al tratar estos asuntos. A la postre se esboza, sin embargo, un problema de fondo.

\section{i. Vida y calidad de vida}

Una primera, muy interesante, es la confusión entre vida y calidad de vida. Elizabeth Price Foley escribió hace poco que en el seno de las legislaciones hay dos paradigmas en choque: uno es el de los movimientos pro-vida que sostienen que la vida comienza con la concepción y debe ser protegida; otro es el que hace prevalecer el concepto de "calidad de vida" por sobre el de "vida", otorgando derecho a la muerte si esa vida no alcanza determinados estándares de calidad mínimos (PRICE FOLEY, 2011, p. 265). Incluso, podríamos pensar a partir de éste modelo, que ese derecho podría ser ejercido por el representante legal del sujeto que no arriba a los estándares si éste no pudiera expresar por sí mismo el desagrado de vivir por debajo del estándar mínimo.

Subyace una presunción de que ese estándar mínimo indudablemente haría preferible no vivir. Sin embargo, la misma autora señala la "paradoja de la discapacidad" ("dishability paradox", consistente en que determinados pacientes que viven en circunstancias que para muchas personas serían inhumanas, para ellos son consideradas aceptables mínimos (PRICE FOLEY, 2011, p. 244). Claro que ésta paradoja, acentúa el criterio de la autodeterminación en torno a la aceptabilidad de un modo de vida. Sin embargo, la autodeterminación entra en severa crisis cuando el sujeto sobre el que se toma la decisión es incapaz aquí y ahora de decidir sobre un hecho tan radical como lo es el de terminar con su vida humana. Estas consideraciones toman especial relieve al tratar del aborto por una vida que no merece vivirse. Si se admitiera que la madre, gracias al buen diagnóstico prenatal del médico, decidiera que esa vida no merece la pena vivirse, esa decisión sería una decisión terminal e irreversible tomada en representación (patria potestad) del no nacido. A lo mejor, ese no nacido hubiera preferido vivir "esa" vida que es indeseable a los ojos del adulto.

O peor, la potestad de realizar esa decisión implica en realidad no sólo un ius vitae ac mortis (un derecho de decidir sobre la vida y la muerte de los propios hijos, en un retroceso del más radical que ha visto la historia en materia de patria potestad, bajo la asepsia de la técnica); sino que podría expresar una suerte de sanción de la ley 
del más fuerte. Los padres podrían desentenderse de la responsabilidad procreativa. Criarían sólo a los hijos que fueran de su agrado o los elegirían ${ }^{33}$, según los estándares de sanidad que consideraran no sólo acordes a lo que ellos soportarían si estuvieran en el lugar del hijo, sino acordes a su medida de egoísmo o cansancio en el proceso de crianza. La protagonista de la novela de Agatha Christie The Mirror crack'd..., según uno de los personajes, habría devuelto a sus hijos adoptivos a la institución de donde provenían, porque había encontrado que era más agradable la idea abstracta de tener hijos que el día a día de educarlos.

Este asunto no ha sido ajeno a las consideraciones de la doctrina y los comités científicos. ¿Cuándo puede decirse que la condición es tan seria que la vida no merezca la pena ser vivida? Algunos síndromes podrían entrar en esa categoría, pero como apuntó oportunamente el Comité Consultivo de la HFEA en Inglaterra, esta valoración depende de muchas circunstancias y disposiciones familiares (SCOTT, 2009, pp. 183 y ss). El riesgo de establecer un criterio de utilidad queda latente. Habría una línea cero o de punto de partida. Los niños por debajo de esa línea o estándar, por cuidado de su bienestar, no deberían nacer. Más aún, los padres, en el futuro, podrían resultar responsables por haber permitido el nacimiento de un niño por debajo de la línea cero (WILKINSON, 2010, pp. 75 y ss).

El deber de asistencia de los padres en educar a los hijos puede ser gravoso. ¿Hasta qué punto es lícito que los padres se desembaracen de sus hijos una vez concebidos, porque debido a una malformación supondrán un cuidado especial? ¿Considerando la maleabilidad de lo humano, es lícito negar la chance de los niños con discapacidades diversas de vivir "esa" vida? ¿Los hijos podrían hacer lo mismo con sus progenitores, cuándo ellos a su turno requieran cuidados no previstos debido a los devaneos de la naturaleza y su desgaste? Nuevamente, no son preguntas retóricas, sino reflexiones en torno al nuevo modo humano que propone la operabilidad técnica.

\section{ii. b) Discriminación genética ${ }^{34}$}

El TEDH ha interpretado de manera dinámica: Si esos niños tienen malformaciones génicas, los padres podrán quejarse y pedir indemnización por la desgracia de no haberlos podido abortar a tiempo mensaje de la opción es polémico. Sin embargo, los niños, dice la Convención sobre los Derechos del Niño en su Art. 2, no serán sujetos a ningún tipo de discriminación. El TEDH se resguarda de la aplicación del Art. 2 diciendo que no resulta claro cuando comienza la existencia humana $a^{35}$. En el caso, se trataba de una niña ya nacida, y la posibilidad de hacer el aborto se dejó de lado por la viabilidad extrauterina de la niña.

33 Como sugiere Stephen WILKINSON (2010).

34 Ver a este respecto en informe "Discriminación genética" (Centro de Bioética, Persona y Familia, s.d.)

35 Parágrafo 186, RR. v. Poland. 
En este sentido, la autora R. Scott, al analizar la ley inglesa y los criterios éticos que deben regir estas decisiones, establece una serie de parámetros que considera de importancia. Primero, sostiene que existe una proporcionalidad entre la duración del embarazo y la exigencia de justificación para su interrupción. Vale decir, cuánto más dura el embarazo, más graves habrán de ser las razones para interrumpirlo. La razón es de costos. Es más costoso (a nivel económico y emocional) interrumpir un embarazo avanzado que un embarazo temprano, menos visible o perceptible por los progenitores. De allí que nuevamente, en virtud de costos, resulte preferible el diagnóstico preimplantatorio que puede hacerse en la fecundación in vitro, que la interrupción de un embarazo fruto de una concepción natural (SCOT'T, 2009).

En todo caso, el diagnóstico prenatal no es malo en sí mismo. Ahora bien, si el diagnóstico prenatal es una herramienta para seleccionar niños que tengan un detérminado "estándar de calidad", o adultos (entre ellos los padres) podrán decidir qué niños quieren criar y cuáles no, sobre la base de que no tengan "fallas genéticas", el estándar del Art. 2 de la Convención sobre los Derechos del Niño parece quedar comprometido. El diagnòstico prenatal se convertiría así en una herramienta eugenésica.

\section{iii. c) Un problema de fondo}

Consideraciones como las que trae R. Scott hacen pensar que engendrar hijos en varios registros se asemeja cada vez más a un asunto de economía de capitales y mercado $^{36}$. Hablar de costos, cargas y beneficios referiéndose a hijos, es un indicio de una deshumanización llamativa.

El hombre, la vida humana y la condición humana se tornan operables y es necesario justificar esta lógica de mercado que es autónoma y colectiva (y termina por instrumentar al hombre y al científico). De resultas, la discriminación genética está justificada con razones de nuevos paradigmas: es ético que una vida de condición inviable o fallida no sea vivida, aún si su titular no está en condiciones de tomar la decisión (por falta de competencia, por ser humano y no persona en el sentido tecnificado y operable del término, no en la óptica ya superada de los Tratados de Derechos Humanos). La dinámica evolutiva presidida por la ley del más fuerte habrá vuelto a imponerse. 


\section{La perplejidad ante el reclamo por un niño vivo del que se alega que no debió haber nacido}

No puede cerrarse este comentario sin recordar una cita del Juez Borrego Borrego, en el caso "Tysiac contra Polonia ${ }^{37 " . ~ E l ~ c a s o ~ T y s i a c ~ s e ~ r e f i e r e ~ a l ~ m i s m o ~}$ tópico que el caso R. R. De la misma manera en que se multiplican los antecedentes sobre transexualismo con Gran Bretaña, con Polonia -que ya legalizó el aborto hasta las 12 semanas con un rigor mediano- parece ser éste el tópico repetido.

Pues bien, la Sra. Tysiac estaba embarazada de su tercer hijo, y algún médico le indicó que podría ser que su miopía ya muy avanzada podría empeorar en caso de llevar a término el embarazo. Ningún médico coincidió con ese criterio y la Sra. Tysiac no pudo abortar como demandaba. Dio a luz, y varios meses más tarde se constató que había empeorado gravemente su miopía. Nueve médicos distintos evaluaron su situación, entre ellos oftalmólogos y ginecólogos de primer nivel. Todos ellos concluyeron que la evolución oftalmológica de la Sra. Tysiac no tenía vínculo causal con el embarazo. Sin ese vínculo causal establecido, con un niño que contaba con 8 años de edad obtuvo una condena para Polonia y una indemnización a su favor por veinticinco mil euros. El fundamento fue que el Estado debió haber asegurado el cumplimiento efectivo de la cláusula que permite decidir el aborto en el caso de que el embarazo constituya una "amenaza" para la salud de la madre. Esa amenaza estaba constituida fundamentalmente por la sensación subjetiva de amenaza que había experimentado la madre, pero no pudo ser acreditada objetivamente en ninguna instancia.

En esa ocasión, decíamos, el magistrado español Borrego Borrego, asentaba en su voto de disenso:

Todos los seres humanos nacen libres e iguales en dignidad y derechos. Hoy la Corte ha decidido que un ser humano fue nacido como resultado de una violación a la Convención Europea de los Derechos Humanos. De acuerdo a este razonamiento, hay un niño polaco, actualmente de seis años de edad, cuyo derecho de nacer contradice la Convención.

Nunca hubiera pensado que la Convención iría tan lejos, y lo encuentro atemorizante ${ }^{38}$.

37 CASE OF TYSIĄC v. POLAND, (Application no. 5410/03), Juzgado en Estrasburgo el 20 de Marzo de 2007.

38“All human beings are born free and equal in dignity and rights. Today the Court has decided that a human being was born as a result of a violation of the European Convention on Human Rights. According to this reasoning, there is a Polish child, currently six years old, whose right to be born contradicts the Convention. I would never have thought that the Convention would go so far, and I find it frightening." 
Hoy, hay una niña con síndrome de Turner de 9 años, casi diez, cuya vida es un signo de contradicción. Los nuevos derechos humanos, tal vez hubieran preferido que la madre pudiera optar, caso en el cuál la niña estaría hoy muerta.

\section{El nuevo humano y la tecnociencia}

Dice Gilbert Hottois (s.d.):

Pero, aquello que la postmodernidad no puede ser, es un espacio caótico dónde el más fuerte terminaría por dominar, solo, destruyendo todas las alteridades que buscan afirmarse por sí mismas. Un mundo de tal suerte no se enriquece, se empobrece.

Lo cierto es que el hombre tiene una capacidad de adaptación única. Lo que no es cierto es que todas las expresiones de lo humano lo humanicen. Tal vez algunas expresiones son más atávicas. Tal vez los retrocesos en la comprensión o inteligibilidad de lo propiamente humano se instalen paradigmáticamente, como señala Hottois; y, arrastrados por la tecnocienci ${ }^{39}$, el discurso científico se generalice en esa dirección.

Siempre habrá luces en la historia que permitirán recordar modelos o arquetipos de humanidad que tal vez, con nuevos paradigmas, desaparezcan. Pienso, por ejemplo, en la Madre Teresa de Calcuta, pidiendo evitar el aborto ${ }^{40}$ y a cambio ofreciendo asumir ella el cuidado y otorgar una posterior crianza de aquellos niños por nacer con el fin de evitar su muerte; o, en el cuidado que hacía de los pobres moribundos, tal vez hediondos, desagradables, deformes, semi-inconscientes o inmorales, sufrientes -pero humanos en sus ojos- en las veredas sucias de Calcuta.

39 En este sentido: HOTTOIS, 1999, p. 67, sobre la necesidad de la mediación del signo entre la técnica y el hombre, la apropiación simbólica humanizaría. Con cita de Habermas, sobre la apariencia neutral de la técnica y su verdadero carácter ideológico.

40 "Por favor no mate a ese niño. Yo quiero a ese niño. Por favor denme a ese niño. Yo estoy dispuesta a aceptar cualquier niño que esté por ser abortado.” Madre Teresa de Calcuta, Carta sobre el aborto. 


\section{Referencias}

CENTRO DE BIOÉTICA, PERSONA Y FAMILIA. Discriminación Genética. Disponible en http://www. centrodebioetica.org/biblioteca/discriminaciongenetica.pdf

CHÉNARD, Isabelle. Normalisation du vocabulaire du droit des délits. Dossier de synthèse. Group wrong, Centre de Traduction et Documentation Juridique (Université d'Ottawa) délits 7H (2008-01-28) [http:// www.cttj.ca/Documents/droit_delits/wrong_CTDJ_7H.pdf], que puede consultarse también en 9 Rev. C.L. Francais 421 (2007).

DE LORENZO, Miguel Federico; TOBÍAS, José W., “Complejo de negocios unidos por un nexo (El ligamen negocial)", LA LEY 1996-D, 1387

ENGELHARDT, Hugo Tristram, The foundation of bioethics, Oxford University Press, 1996.

FEDERATION FOR WOMEN AND FAMILY PLANNING. Statement in Case RR vs. Poland. Disponible en http://www.federa.org.pl/index.php?option $=$ com_content\&view $=$ article\&id=702:statementca serrvpoland\&catid=78:news\&Itemid=120, consultada el 30/5/2011.

GARNER Bryan A. (editor). Black’s Dictionary, West Group, 8th Edition, 2004.

HOT'TOIS, Gilbert y MISSA, Jean Noël, Nouvelle Encyclopédie de Bioéthique, Bruxelles: De Broeck \& Larcier, 2001.

HOTTOIS, Gilbert, El paradigma bioético: Una ética para la tecnociencia, Antrhopos, 1999.

HOTTOIS, Gilbert, "La technoscience : entre technophobie et technophilie », s.d., publicado en http:// download.sfrs.fr/media-1/canalu/utls/download/pdf/190100.pdf (consultado en 26/8/2011).

KLUGMAN, Barbara ; BUDLENDER, Debbie. Advocating for Abortion Access: Eleven Country Studies. Johannesburg/ South Africa: The Women's Health Project - University of the Witwatersrand, 2001.

LAFFERRIÈRE, Implicaciones jurídicas del diagnóstico prenatal. El concebido como hijo y como paciente, Buenos Aires: EDUCA, 2010.

MÉMÉTEAU, Gérard, «L'action de vie dommageable », Semaine juridique, 2000, I.

PRICE FOLEY, Elizabeth, The law of life and death, Harvard University Press, 2011.

ROMERO COLOMA, Aurora, "Las acciones de wrongful life y su problemática jurídica”, Diario La Ley España, n $7224 / 2009$.

SCOT'T, Rosamund, "Selective termination of pregnancy and preimplantory genetic diagnosis: some ethical issues in the interpretation of legal criteria", en AAVV, Reproductive Genetics, Royal College of Obstetricians and Gynaecologists, 2009, pp. 183 y ss

TEDH. Caso R.R. v. POLAND. (no. 27617/04), 26 de Mayo de 2011.

TEDH. Caso TYSIĄC v. POLAND, (no. 5410/03), 20 de Marzo de 2007. Puede consultarse en línea en: http:/ / cmiskp.echr.coe.int/tkp197/view.asp?action=html\&documentId=814538\&portal=hbkm\&source=ext ernalbydocnumber\&table $=$ F69A27FD8FB86142BF01C1166DEA398649

WILKINSON, Stephen, Choosing tomorrow's children, Oxford Unversity Press, 2010. 


\section{Ursula Cristina Basset}

ucbasset@gmail.com

Doctor en Ciencias Jurídicas, Facultad de Derecho, Pontificia Universidad Católica Argentina "Santa María de los Buenos Aires" (2004). Profesora a cargo de Cátedras de Derecho de Familia y Sucesiones, Pontificia Universidad Católica Argentina. Investigadora(UCA), Miembro del Instituto de Bioética de la Academia Nacional de Ciencias Morales y Políticas (Argentina). Abogada 